\title{
Investigation of blistering kinetics in hydrogen implanted aluminium nitride
}

\author{
R Singh ${ }^{1}$, R Scholz ${ }^{2}$, S H Christiansen ${ }^{2}$ and U Gösele ${ }^{2}$ \\ ${ }^{1}$ Department of Physics, Indian Institute of Technology Delhi, Hauz Khas, New Delhi 110016, India \\ ${ }^{2}$ Max Planck Institute of Microstructure Physics, Weinberg 2, D-06120 Halle, Germany \\ ${ }^{3}$ Martin Luther Universität Halle-Wittenberg, Hoher Weg 8, D-06099 Halle, Germany
}

Received 17 October 2007, in final form 28 January 2008

Published 26 February 2008

Online at stacks.iop.org/SST/23/045007

\begin{abstract}
Epitaxial layers of aluminium nitride (AIN) grown on sapphire by hydride vapour phase epitaxy (HVPE) were implanted with $100 \mathrm{keV}$ hydrogen, $\mathrm{H}_{2}^{+}$, ions with doses in the range of $5 \times 10^{16}-2.5 \times 10^{17} \mathrm{~cm}^{-2}$ and subsequently annealed in ambient air at temperatures between 450 and $750{ }^{\circ} \mathrm{C}$ in order to determine the kinetics of surface blister formation in AlN. The Arrhenius plot of the blistering time versus temperature shows two different activation energies for the formation of surface blisters: $0.44 \mathrm{eV}$ in the higher temperature regime of $550-750{ }^{\circ} \mathrm{C}$ and $1.16 \mathrm{eV}$ in the lower temperature regime of $450-550{ }^{\circ} \mathrm{C}$. The implantation-induced damage was analyzed by cross-sectional transmission electron microscopy, which revealed a band of defects extending from 330 to $550 \mathrm{~nm}$ from the surface of AlN. The XTEM image of the implanted and annealed AlN displayed clearly the formation of microcracks that ultimately lead to the formation of surface blisters.
\end{abstract}

(Some figures in this article are in colour only in the electronic version)

\section{Introduction}

III-V nitrides have a wide range of applications in the field of optoelectronics as well as high frequency and high power electronic devices. In general, the epitaxial layers of these nitrides for various device applications are grown on lattice and thermal mismatched substrates such as sapphire and SiC. The growth of the epitaxial layers on foreign substrates is carried out since the single crystals of GaN and AlN are very expensive and are mostly available in small sizes [1-3]. In the case of AlGaN alloys, especially those with a high $\mathrm{Al}$ content, AlN offers a better lattice and thermal expansion match to AlGaN alloys in comparison to GaN. These high $\mathrm{Al}$ content $\mathrm{AlGaN}$ epitaxial layers are required for ultraviolet (UV) electro-optical applications such as UV light-emitting diodes, UV laser diodes and solar-blind UV photodetectors [4-7]. It has recently been shown that for the growth of high crystalline quality epitaxial layers required for these UV photonic devices, single crystal AlN substrates are very useful $[6,7]$. But the single crystal substrates of AlN are extremely expensive. Recently, Crystal IS, Inc. USA has announced the growth of 2 inch diameter AlN wafers having ultra-low density of dislocations $\left(\sim 10^{4} \mathrm{~cm}^{-2}\right)$ [3, 8]. A very promising method to fabricate low-cost and high structural quality substrates, comparable to single crystals of AlN substrates, for the epitaxial growth of high $\mathrm{Al}$ content $\mathrm{AlGaN}$ layers is direct wafer bonding and layer transfer of thin films of AlN via highdose hydrogen implantation and layer splitting [9-11]. The free-standing AlN substrate can be utilized to transfer multiple layers on other foreign substrates. This process is based upon the agglomeration of hydrogen-implantation-induced platelets upon annealing and the subsequent formation of overpressurized microcracks. For the case of the implanted wafer bonded to a handle wafer, splitting of a thin slice of material parallel to the bonding interface occurs [9-13]. For this process to occur, a narrow parameter window of implantation dose, annealing temperature and time has to be defined since the layer splitting is a strongly material-dependent process. The physical mechanisms leading to the process of layer splitting can be conveniently investigated by studying the development of surface blisters in hydrogen implanted and annealed but unbonded wafers [14-16]. There are no reports in the literature regarding hydrogen-implantationinduced blistering in AlN. In the present investigation, we have performed a systematic study of the formation of surface blisters on hydrogen implanted and annealed AlN layers grown epitaxially on sapphire. 


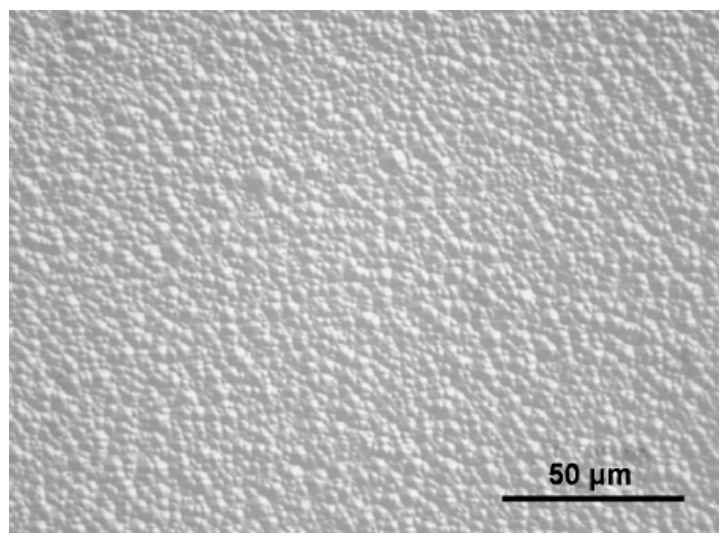

Figure 1. Nomarski optical image of the surface of a pristine AlN epitaxial layer.

\section{Experimental details}

AlN epitaxial layers about $2 \mu \mathrm{m}$ in thickness were grown on 2 inch $\left(\begin{array}{llll}0 & 0 & 0 & 1\end{array}\right) c$-plane sapphire substrates using metal hydride vapour phase epitaxy (HVPE). These AlN/sapphire wafers were purchased commercially from TDI, Inc. USA. The AlN epitaxial layers were implanted at room temperature with $100 \mathrm{keV} \mathrm{H}_{2}^{+}$ions with various doses in the range of $5 \times 10^{16}$ $2.5 \times 10^{17} \mathrm{~cm}^{-2}$. During implantation the sample surface normal was inclined at $\sim 7^{\circ}$ relative to the incident ion beam in order to avoid channelling effects. The hydrogen implantation was performed at Ion Beam Services (IBS), France. After implantation the wafers were cut into small pieces $(\sim 3 \times$ $3 \mathrm{~mm}^{2}$ ) and annealed at different temperatures ranging from 450 to $750{ }^{\circ} \mathrm{C}$. The annealing was carried out in an air ambient box-type furnace. The formation of optically detectable surface blisters on AIN epitaxial layers was observed using a Nomarski optical microscope. The annealing time required to form optically detectable blisters at a particular temperature is defined as the blistering time at that temperature. In this way the blistering times were determined at different temperatures ranging from 450 to $750^{\circ} \mathrm{C}$. The microstructural characterization of the implantation-induced damage in AlN was performed using cross-sectional transmission electron microscopy (XTEM). The XTEM measurements were carried out using a Philips CM20T machine operated at $200 \mathrm{kV}$.

\section{Results and discussion}

The surface of the pristine AlN epitaxial layer was found to be quite rough, as shown in the Nomarski optical image of figure 1 . The surfaces were found to have a large number of hillocks having the lateral size of a few micrometres. The typical RMS roughness of the surface, as measured by atomic force microscopy, was found to be about $20 \mathrm{~nm}$ on a $10 \times$ $10 \mu \mathrm{m}^{2}$ scan area with a peak-to-valley height of about $140 \mathrm{~nm}$, as shown in figure 2. In the case of hydrogenimplanted AlN, the wafers were implanted with a dose of $2.0 \times 10^{17} \mathrm{~cm}^{-2}$ or higher exhibited surface blisters in the as-implanted state. In contrast, the $\mathrm{AlN}$ wafers that were implanted with a dose of $1.0 \times 10^{17}$ or $1.5 \times 10^{17} \mathrm{~cm}^{-2}$

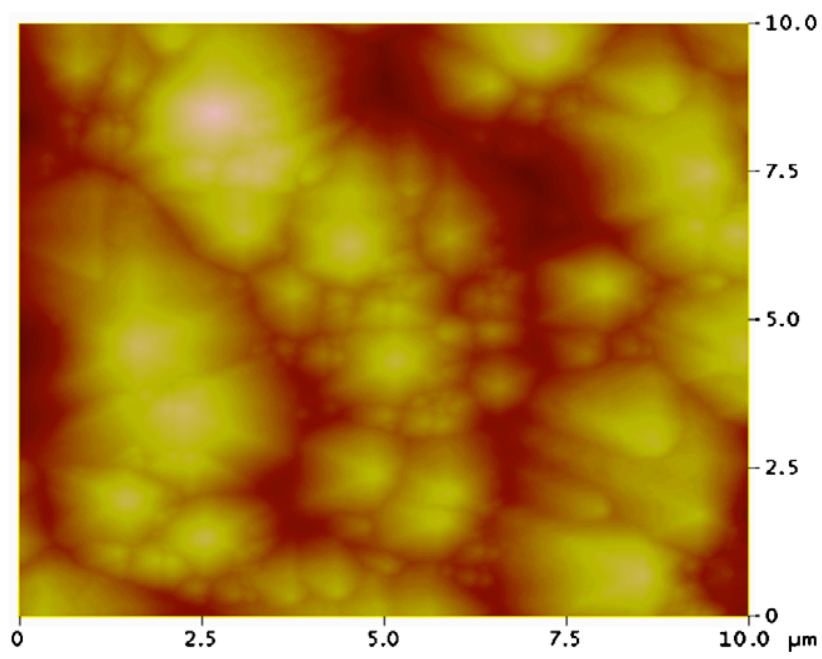

Figure 2. AFM image of the surface of a pristine AlN epitaxial layer. The RMS roughness of the surface is about $20 \mathrm{~nm}$ and the $Z$ range is about $140 \mathrm{~nm}$.

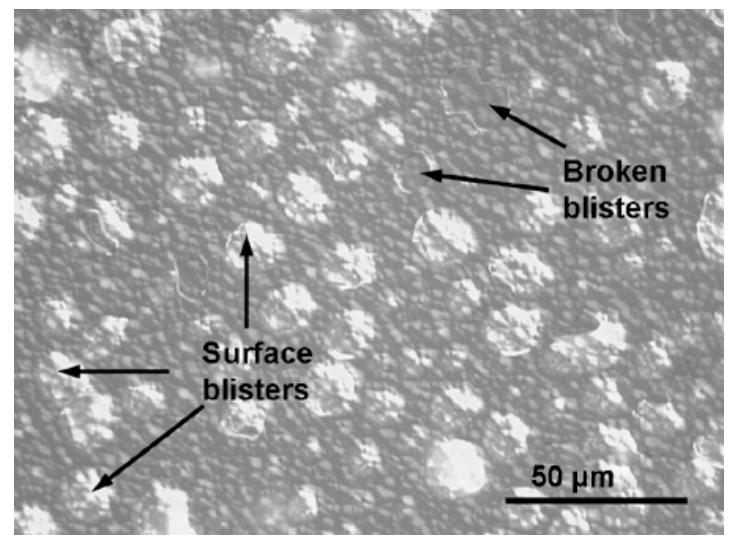

Figure 3. Nomarski optical image of the surface of an implanted and annealed AlN epitaxial layer. The implantation was performed with $100 \mathrm{keV} \mathrm{H}_{2}^{+}$ions with a dose of $1 \times 10^{17} \mathrm{~cm}^{-2}$ and then the annealing was carried out at $500{ }^{\circ} \mathrm{C}$ for $1 \mathrm{~h}$.

showed surface blisters only after post-implantation annealing at higher temperatures. The sample implanted with a dose of $5.0 \times 10^{16} \mathrm{~cm}^{-2}$ did not show any blistering even after post-implantation annealing up to $800{ }^{\circ} \mathrm{C}$ for $2 \mathrm{~h}$. A typical Nomarski optical image of the AlN surface implanted with a dose of $1.0 \times 10^{17} \mathrm{~cm}^{-2}$ and subsequently annealed at $500{ }^{\circ} \mathrm{C}$ for $1 \mathrm{~h}$ is shown in figure 3 . The surface blisters have diameters in the range of 10-20 $\mu \mathrm{m}$ and their heights are about a few hundreds of nanometres (figure 3). A systematic blistering study was carried out for the AlN wafer that was implanted with a dose of $1.0 \times 10^{17} \mathrm{~cm}^{-2}$. The Arrhenius plot of the blistering time as a function of the reciprocal temperature is shown in figure 4 . It can be clearly observed from this figure that there are two different activation energies for the formation of surface blisters. The activation energy is $0.44 \mathrm{eV}$ in the higher temperature regime of $550-750{ }^{\circ} \mathrm{C}$ and $1.16 \mathrm{eV}$ in the lower temperature regime of $450-550{ }^{\circ} \mathrm{C}$. A similar kind of behaviour with two activation energies has been observed earlier in the case of hydrogen/helium implantation 


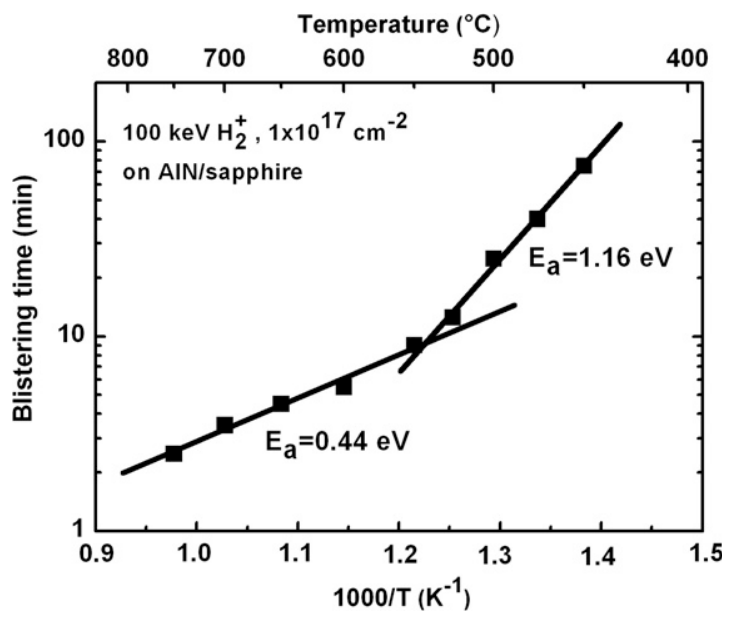

Figure 4. Arrhenius plot of the blistering time as a function of reciprocal temperature for AlN implanted by $100 \mathrm{keV} \mathrm{H}_{2}^{+}$ions with a dose of $1 \times 10^{17} \mathrm{~cm}^{-2}$.

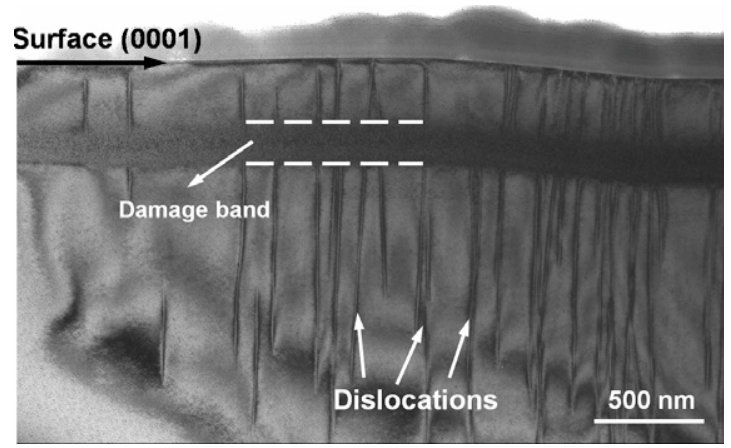

Figure 5. XTEM image of the as-implanted AlN with $100 \mathrm{keV} \mathrm{\textrm {H } _ { 2 } ^ { + }}$ ions with a dose of $1 \times 10^{17} \mathrm{~cm}^{-2}$. The linear defects running perpendicular to the surface are grown-in threading dislocations from the growth process having already been present before the hydrogen implantation.

of other semiconductors such as $\mathrm{Si}, \mathrm{SiGe}, \mathrm{GaAs}$, InP and GaN [11-17]. As in other semiconductors, the lower activation energy appears to be correlated with the free atomic diffusion of hydrogen in the AlN lattice while the higher activation energy seems to be related to the diffusion of hydrogen limited by trapping-detrapping phenomena in the AlN [18].

A cross-sectional TEM image of the hydrogen asimplanted AIN sample is shown in figure 5. It shows a damage band consisting of defects such as clusters of vacancies and interstitials that are induced inside the AlN lattice due to the direct elastic collisions of the hydrogen ions with the AlN atoms. The linear defects running perpendicular to the surface are grown-in threading dislocations from the growth process having already been present before the hydrogen implantation. The damage band extends between 330 and $550 \mathrm{~nm}$ from the surface in the AlN sample. In comparison, the projected range and longitudinal straggling of $100 \mathrm{keV} \mathrm{H}_{2}^{+}$ ions in AlN, as calculated using the Monte Carlo simulation program SRIM2006 [19], is $340 \mathrm{~nm}$ and $50 \mathrm{~nm}$, respectively. Figure 6 shows the XTEM image of the hydrogen implanted and annealed AlN sample at $500{ }^{\circ} \mathrm{C}$ for $10 \mathrm{~min}$ (the blistering time at $500{ }^{\circ} \mathrm{C}$ is $12.5 \mathrm{~min}$ ). A number of microcracks have

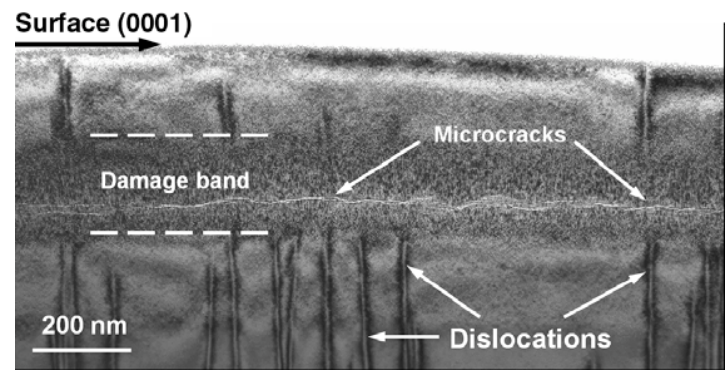

Figure 6. XTEM image of the AlN with $100 \mathrm{keV} \mathrm{H}_{2}^{+}$ions with a dose of $1 \times 10^{17} \mathrm{~cm}^{-2}$ and annealed at $500{ }^{\circ} \mathrm{C}$ for $10 \mathrm{~min}$.

formed inside the damage band and are mostly oriented parallel to the $A I N\left(\begin{array}{llll}0 & 0 & 0 & 1\end{array}\right)$ surface. These microcracks are ultimately responsible for the formation of surface blisters due to the hydrogen over-pressure inside the microcracks upon annealing at higher temperatures.

The minimum hydrogen dose required for the surface blistering in AlN is found out to be about $1.0 \times 10^{17} \mathrm{H}_{2}^{+} \mathrm{cm}^{-2}$. In comparison to other semiconductors such as $\mathrm{Si}, \mathrm{Ge}, \mathrm{InP}$, $\mathrm{GaAs}$ and $\mathrm{SiC}$, this dose value is about three times higher [11-15]. For example, the minimum hydrogen dose required to observe surface blistering in $\mathrm{Si}, \mathrm{Ge}$ or $\mathrm{SiC}$ is about $3 \times$ $10^{16} \mathrm{H}_{2}^{+} \mathrm{cm}^{-2}[11,13,14]$. It is known from the literature that the group III nitrides such as AlN and GaN exhibit very efficient dynamic annealing of the implantation-induced defects [20-24]. In the process of blistering, the implanted hydrogen interacts with the implantation-induced damage inside the semiconductor lattice that ultimately leads to the formation of extended defects such as nanovoids/nanoplatelets $[9,10,13,25]$. Upon thermal annealing of the hydrogenimplanted semiconductor, these nanovoids/nanoplatelets grow in size and agglomerate together due to the overpressure of hydrogen gas filled within them ultimately leading to the formation of large area microcracks. These microcracks subsequently lead to the formation of surface blisters upon annealing. Hence, a minimum amount of lattice damage is required in the semiconductor so that the hydrogen interaction process with the defects efficiently leads to the formation of nanovoids/nanoplatelets. Since in the nitride semiconductors, the dynamic annealing of the implantation-induced defects is very efficient, higher dose of hydrogen is required in comparison to other semiconductors to induce minimum damage inside the lattice. Similar to the case of AlN, GaN also exhibits an efficient dynamic annealing of the implantationinduced defects and hence the minimum hydrogen dose required for surface blistering in $\mathrm{GaN}$ is also quite high $\left(\sim 1.3 \times 10^{17} \mathrm{H}_{2}^{+} \mathrm{cm}^{-2}\right)$, as observed earlier by a few studies $[16,25,26]$. Thus, it is concluded that the III nitrides require higher values of minimum hydrogen dose in comparison to other semiconductors such as $\mathrm{Si}, \mathrm{Ge}, \mathrm{GaAs}, \mathrm{SiC}$ and $\mathrm{InP}$ for the surface blistering to occur due to their higher radiation resistance.

\section{Conclusions}

AlN epitaxial layers were implanted with $100 \mathrm{keV} \mathrm{H}_{2}^{+}$ ions at various doses and subsequently annealed at higher 
temperatures in order to observe the formation of surface blisters in AlN. The blistering time was determined at various temperatures between 450 and $750{ }^{\circ} \mathrm{C}$ for the AlN wafer implanted with a dose of $1.0 \times 10^{17} \mathrm{~cm}^{-2}$. The blistering kinetics studies revealed two different activation energies for the formation of surface blisters: $0.44 \mathrm{eV}$ in the higher temperature regime of $550-750{ }^{\circ} \mathrm{C}$ and $1.16 \mathrm{eV}$ in the lower temperature regime of $450-550{ }^{\circ} \mathrm{C}$. The lower activation energy is related to the free atomic diffusion of hydrogen in AlN while the higher activation energy is related to the diffusion of hydrogen limited by the trapping-detrapping mechanism. The XTEM images of the implanted AIN layer showed that a damage band is formed in the AlN epilayer and after annealing at higher temperatures, large area microcracks are formed inside the damage band. These microcracks are ultimately responsible for the formation of surface blisters in the implanted AlN layers. It remains to be shown that, based on the results on hydrogen-implantation-induced blistering presented in this paper, thin layers of AIN can be transferred from free-standing AlN wafers to appropriate substrates by wafer bonding combined with hydrogen-implantation-induced layer splitting.

\section{Acknowledgments}

The authors are thankful to Mrs S Hopfe for the XTEM specimen preparation. The work is supported financially by the Max Planck Society (MPG), Germany under the cooperation scheme of Max Planck Partner Group at Indian Partner Institutions and co-funded by the Department of Science and Technology (DST), India. The authors also thank the German Federal Ministry of Education and Technology (BMBF) for partial support in the framework of the CrysGaN project.

\section{References}

[1] Gibbart P 2004 Rep. Prog. Phys. 67667

[2] Schujman S B, Schowalter L J, Liu W and Smart J 2006 Proc. SPIE $612161210 \mathrm{~K}$
[3] Bondokov R T, Morgan K E, Slack G A and Schowalter L J 2007 Mater. Res. Soc. 955

[4] Li J, Fan Z Y, Dahal R, Nakarmi M L, Lin J Y and Jiang H X 2006 Appl. Phys. Lett. 89213510

[5] Taniyasu Y, Kasu M and Makimoto T 2006 Nature 441325

[6] Ren Z et al 2007 Appl. Phys. Lett. 91051116

[7] Kneissl M, Yang Z, Teepe M, Knollenberg C, Schmidt O, Kiesel P, Johnson N M, Schujmann S and Schowalter L J 2007 Appl. Phys. Lett. 101123103

[8] See website: http://www.crystal-is.com

[9] Bruel M 1995 Electron. Lett. 311201

[10] Tong Q-Y and Gösele U 1999 Adv. Mater. 111404

[11] Christiansen S H, Singh R and Gosele U 2006 Proc. IEEE 942060

[12] Radu I, Szafraniak I, Scholz R, Alexe M and Gösele U 2003 Appl. Phys. Lett. 822413

[13] Cioccio L Di, Letiec Y, Letertre F, Jaussaud C and Bruel M 1996 Electron. Lett. 321144

[14] Tong Q-Y, Gutjahr K, Hopfe S, Gösele U and Lee T H 1997 Appl. Phys. Lett. 701390

[15] Singh R, Radu I, Scholz R, Himcinschi C, Gosele U and Christiansen S H 2006 J. Lumin. 121379

[16] Singh R, Radu I, Gösele U and Christiansen S H 2006 Phys. Stat. Sol. c 31754

[17] Singh R, Radu I, Reiche M, Scholz R, Webb D, Gösele U and Christiansen S H 2005 Mater. Sci. Eng. B 124-5 162

[18] Limpijumnong S and Van de Walle C G 2001 Phys. Status Sol. b 228303

[19] Ziegler J F, Biersack J P and Littmark U 1985 The Stopping and Range of Ions in Solids (New York: Pergamon)

[20] Kucheyev S O, Williams J S, Zou J, Jagadish C, Pophristic M, Guo S, Ferguson I T and Manasreh M O 2002 J. Appl. Phys. 923554

[21] Kucheyev S O, Williams J S, Zou J and Jagadish C $2004 \mathrm{~J}$. Appl. Phys. 953048

[22] Trachenko K 2004 J. Phys.: Condens. Matter 16 R1491

[23] Jiang W and Weber W J 2006 Nucl. Instrum. Meth. Res. B 242431

[24] Zhang C H, Song Y, Sun Y M, Chen H, Yang Y T, Zhou L H and Jin Z F 2007 Nucl. Instrum. Meth. Res. B 256199

[25] Radu I, Singh R, Scholz R, Goesle U, Chrsitiansen S, Bruederl G, Eichler C and Haerle V 2006 Appl. Phys. Lett. 89031912

[26] Tauzin A et al 2005 Electron. Lett. 41668 